\title{
Longterm prediction of failure after treatment of cervical precancer
}

\author{
Arbyn, M.
}

2020-02

Arbyn , M , Gondry , J \& Nieminen , P 2020 , ' Longterm prediction of failure after treatment of cervical precancer ' , BJOG : An International Journal of Obstetrics \& Gynaecology , vol. 127 , no. 3 , pp. 388-388 . https://doi.org/10.1111/1471-0528.16023

http://hdl.handle.net/10138/327209

https://doi.org/10.1111/1471-0528.16023

acceptedVersion

Downloaded from Helda, University of Helsinki institutional repository.

This is an electronic reprint of the original article.

This reprint may differ from the original in pagination and typographic detail.

Please cite the original version. 


\title{
Article type : Mini commentary
}

Corresponding author mail id: marc.arbyn@sciensano.be

Mini commentary on BJOG-19-0729.R1: Long-term predictors of residual or recurrent cervical intraepithelial neoplasia 2-3 after treatment with a large loop excision of the transformation zone: a retrospective study

\section{Longterm predicition of failure after treatment of cervical precancer}

\author{
M. Arbyn ${ }^{1}$, J. Gondry ${ }^{2}$ P Nieminen ${ }^{3}$
}

${ }^{1}$ Unit of Cancer Epidemiology, Belgian Cancer Centre, Sciensano, Brussels, Belgium

${ }^{2}$ Department of Obstetrics and Gynaecology, University Hospital of Amiens, Amiens, France

${ }^{3}$ Department of Obstetrics and Gynaecology, University of Helsinki and University Hospital of Helsinki, Finland

It is common knowledge that presence of neoplastic cells at the margin of the tissue specimen excised because of a cervical intra-epithelial neoplasia of grade 2 or worse (CIN2+) is associated with treatment failure (Ghaem-Maghani, Lancet Oncol 2007; 11:985-93; Arbyn, Lancet Oncol 2017, 18:1665-79). However, presence of high risk Human Papilloma Virus (HPV) posttreatment is a more accurate predictor (substantially higher sensitivity, similar specificity) of residual or recurrent CIN2+ (Arbyn, Gynecol Oncol 2005, 99: S7-S11). These findings were challenged by Fernandez-Montoli et al (published in this BJOG issue) who followed 242 CIN2+ patients treated with large loop excision of the transformation zone (LLETZ) at the Bellvitgein Hospital (Barcelona, Spain), over a period up to 20 years. Seventy five (31\%) of treated women had involved margins, among whom 56\% (42/75) at the endocervical margin, whereas for $13 \%$

This article has been accepted for publication and undergone full peer review but has not been through the copyediting, typesetting, pagination and proofreading process, which may lead to differences between this version and the Version of Record. Please cite this article as doi: 10.1111/1471-0528.16023

This article is protected by copyright. All rights reserved 
(31/242) margin involvement was uncertain. The rate of treatment failure was overall 5.4\% $(13 / 242)$. This rate varied from 1.5\% (2/134) if clear margins, to 5.3\% (4/75) if any involved margin, 9.4\% (3/32) if positive endo-cervical margin and 19.4\% (6/31) if margin status was uncertain. The relative risk of treatment failure associated with any or endo-cervical involved margins, was 3.6 (95\% CI 0.67-19.1) and 6.2 (95\% 1.1-36.0), respectively. Fernandez-Montoli et al reported also post-treatment cytology and HPV data. The most sensitive predictor of therapeutic failure was post-treatment HPV testing (89\%) with HC2 (Qiagen), followed by cytology at cut-off ASC-US+ (54\%) and margin status (33\%). Cytology was the most specific predictor (84\%) followed by HC2 (80\%) and margin status $(69 \%)$. When uncertain margins were considered as positive, the sensitivity increased to $83 \%$, whereas the specificity decreased to $58 \%$. The combination of margin and HPV post-treatment status (for those cases where data for both were available) increased the sensitivity of the prediction of treatment failure to $100 \%(9 / 9)$ but decreased the specificity to $42 \%$.

The Barcelona study perfectly fits to the inclusion criteria of a recent meta-analysis that compared the accuracy of margin involvement and HPV assessment as tests of cure (Arbyn, Lancet Oncol 2017, 18:1665-79). Although the proportion of positive margins was higher in Fernandez-Montoli ( $56 \%$ vs $33 \%$ in the meta-analysis), the rates of residual/recurrent CIN $2+$ were similar $(5.4 \%$ vs $6.6 \%$ [95\% CI 4.9-8.4\%] on average for LLETZ treatments). The accuracy of the margin status in the Barcelona study was lower than in the meta-analysis: sensitivity of $33 \%$ vs $56 \%$ (95\% CI 46 $67 \%$ ) and a specificity of $69 \%$ vs $84 \%$ (CI $80-88 \%$ ) However, HPV testing and the combination of HPV and margin status showed similar accuracy as in the meta-analysis.

Particular to the Barcelona study was the great proportion of uncertain margins and the similar predictive value of uncertain and positive endo-cervical margins.

To conclude, the Barcelona study corroborates prior observations: positive margins are significantly associated with treatment failure but the accuracy of margin status to predict therapeutic failure is poor. On the other hand, a HPV test three to nine months after the excision shows good sensitivity and reasonable specificity.

\section{Disclosure of interests}

MA's institute received funding from DG Research and Innovation of the European Commission (Brussels, Belgium) via the COHEAHR and RISCC projects; and from the European Federation of 
Colposcopy (EFC). MA and JG were supported by the Institut National du Cancer (Paris, France) through the COSPCC project. PN reports grants from the Finnish Cancer Organisations during the conduct of the study. Completed disclosure of interest forms are available to view online as supporting information.

This article is protected by copyright. All rights reserved 